\section{Cátedra Libre de Pueblos Originarios: 10 años de relaciones interculturales con las comunidades de Tucumán, Argentina}

\author{
Olga Liliana Sulca \\ olgalilianasulca@yahoo.com.ar
}

Zulma Segura

zulmasegura73@gmail.com

CERPACU Instituto del Rescate y

Revalorización del Patrimonio Cultural

Universidad Nacional de Tucumán, Argentina.
Cultura(s) en clave de extensión universitaria Desafíos de gestión
RECEPCIÓN: 02/04/19

ACEPTACIÓN FINAL: 30/05/19

\section{Resumen}

El proyecto Cátedra Libre: Pueblos Originarios se inició en 2009 y sigue vigente dentro del ámbito de la Facultad de Filosofía y Letras de la Universidad Nacional de Tucumán (Argentina). Dicha propuesta se direccionó a atender, por un lado, la diversidad étnica del estudiantado que llega a la Facultad, promoviendo la equidad y fomentando su participación. Y, por otro lado, a interactuar con las diferentes comunidades indígenas autorreconocidas dentro del territorio provincial.

Sin duda que estas experiencias han propiciado una instancia favorable no solo en la inclusión de alumnos indígenas que ingresan a esta unidad académica, sino también en cuanto a situar el conocimiento indígena desde otras epistemologías.

En este espacio de la cátedra confluyeron alumnos indígenas y no indígenas, docentes de los distintos niveles educativos, miembros de las diferentes comunidades indígenas y dirigentes indígenas. El presente trabajo dará cuenta de 10 años de esta experiencia.

Palabras clave: interculturalidad, extensión universitaria, participación indígena, aprendizaje, conocimiento.
Free Chair of Indigenous Peoples: 10 years of intercultural relations with Tucumán communities, Argentina

\section{Abstract}

The "Cátedra Libre: Pueblos Originarios" project began in 2009 and is still valid, within the scope of the Faculty of Philosophy and Letters of the National University of Tucumán (Argentina). This proposal was addressed to address on the one hand, the ethnic diversity of the students that come to the Faculty, promoting equity and encouraging their participation. And on the other hand, interact with the different self-recognized indigenous communities within the provincial territory. Undoubtedly, these experiences have led to a favorable instance not only in the inclusion of indigenous students who enter this academic unit, but also allowed placing indigenous knowledge from other epistemologies. In this space of the chair, indigenous and nonindigenous students, teachers from different educational levels, members of the different indigenous communities and indigenous leaders converged. The present work will account for 10 years of this experience

Keywords: interculturality, college extension, indigenous participation, learning, knowledge.
Cátedra Livre de Povos Indígenas: 10 anos de relações interculturais com as comunidades do Tucumán, Argentina

\section{Resumo}

O projeto Cátedra Libre: Povos Originários começou em 2009 e continua em vigência, no âmbito da Faculdade de Filosofia e Letras da Universidade Nacional de Tucumán (Argentina). Esta proposta foi dirigida para abordar, por um lado, a diversidade étnica dos estudantes que chegam à Faculdade, promovendo a equidade e incentivando a sua participação. E por outro lado, interagir com as diferentes comunidades indígenas autorreconhecidas dentro do território provincial. Sem dúvida, essas experiências proporcionaram uma instância favorável não apenas na inclusão de alunos indígenas que ingressam nessa unidade acadêmica, mas também permitiram colocar o conhecimento indígena desde outras epistemologias. Nesse espaço da cátedra, convergiram estudantes indígenas e não indígenas, professores de diferentes níveis educacionais, membros das diferentes comunidades indígenas e dirigentes indígenas. Este trabalho dará conta de 10 anos dessa experiência.

Palavras-chave: interculturalidade, extensão universitária, participação indígena, aprendizagem, conhecimento

Para citación de este artículo: Sulca, O. y Segura, Z. (2019). Cátedra Libre de Pueblos Originarios: 10 años de relaciones interculturales con las comunidades de Tucumán, Argentina.+E: Revista de Extensión Universitaria, 9(10), 60-73. doi: 10.14409/extension.v9i10.Ene-Jun.8318. 


\section{Introducción}

Este artículo presenta el análisis de una experiencia de extensión universitaria e intenta desandar un proceso de 10 años de historia. En esta revisión se discutirán conceptos y posicionamientos asumidos, los cuales incidieron en la toma de decisiones, sobre todo, vinculadas a la itinerancia de este proyecto por los territorios de las comunidades indígenas cuando en un principio se pensó trabajar en los distintos espacios de la ciudad de San Miguel de Tucumán.

La puesta en marcha del proyecto Cátedra Libre: Pueblos Originarios se inició en el año 2009 dentro de la Facultad de Filosofía y Letras de la Universidad Nacional de Tucumán (UNT). Cuando abrimos este espacio de discusión nuestro propósito fue avanzar en un cambio de episteme ya que, para buena parte de la historiografía, la cuestión indígena sigue siendo algo extinto o circunstancial, que forma parte solo de piezas de museos pero no de este presente. Nuestro posicionamiento fue que el conocimiento se sitúe desde los pueblos originarios y así poder realizar un intercambio rico y valioso entre ese saber ancestral y la gnosis de la academia.

La presencia de una Cátedra Libre de Pueblos Originarios en el ámbito de la Facultad de Filosofía y Letras se fundó en la necesidad de abrir un terreno de diálogo e intercambio de ideas entre nuestros alumnos de la Facultad y los miembros de las comunidades indígenas reconocidas ancestralmente.

La experiencia de trabajo con las 16 comunidades reconocidas en el territorio de la provincia de Tucumán nos permitió plantear algunas reflexiones hacia dentro de nuestra universidad y, en especial, hacia la formación superior.

El presente escrito está dividido en tres partes. En la primera de ellas se abordarán las problemáticas epistemológicas que atraviesan los conocimientos indígenas; en la segunda, se planteará la experiencia del proyecto Cátedra Libre: Pueblos Originarios, y en la tercera, cerraremos con algunas implicancias de la propuesta en la educación superior.

\section{Problemáticas epistemológicas y conocimientos indígenas}

El destacado lingüista y teórico de la educación intercultural en América Latina Luis Enrique López (1999) señala que el desarrollo de la interculturalidad y su vinculación con la Educación Intercultural Bilingüe (EIB) data al menos de los años 40 del siglo XX dentro del contexto de América Latina. Pero la preocupación por los contenidos y planes de estudio dirigidos a la población indígena se iniciaría recién a mediados de la década de 1970. Aquí los intereses y discusiones no solo se centraban en la barrera idiomática y contenidos impartidos sino en la recuperación e incorporación de saberes y conocimientos indígenas dentro de los contenidos curriculares.

Con distintos matices, la interculturalidad fue impregnando las aulas de las escuelas primarias, secundarias y de formación docente de nivel superior a lo largo de América Latina. Desde la década de 1990, en países como Bolivia, Colombia y Ecuador, la interculturalidad fue articulándose con los procesos políticos del sistema democrático, y así las demandas de los pueblos y naciones indígenas no solamente se centraron en el campo educativo sino que se desplazaron a la cuestión del territorio, a una mayor participación política, al acceso a una salud intercultural, a la defensa del medio ambiente, etc. Los movimientos indígenas buscaron una educación que reconociera la diversidad con calidad pero, fundamentalmente, un 
sistema educativo que asegurara la posibilidad de seguir siendo diferentes (Prada y López, 2009). En ese sentido, un sector de las sociedades latinoamericanas planteaba cambios de paradigmas en el campo educativo, y esto confluía con las ideas de las organizaciones indígenas, las que empezaron a construir las bases de una educación propia que satisfacía sus necesidades. De esa manera, la educación empezaba a responder al desafío contemporáneo de la interculturalidad que articulaba y expresaba la multiculturalidad latinoamericana.

Para Luis Enrique López, "la multiculturalidad no es otra cosa que un hecho o una situación dada que caracteriza a una realidad determinada, mientras que la interculturalidad se constituye en un proyecto o utopía que es necesario construir" (2004:451). A esta reflexión nos remiten Delgado y Mariscal (2007) cuando hablan de una intraculturalidad y una filosofía intercultural a través de la cual podremos descifrar la identidad latinoamericana. Avanzar en la intraculturalidad es posicionar el conocimiento dentro de las mismas comunidades y/o pueblos indígenas; esta perspectiva les permitirá fortalecerse y conocerse a sí mismas para después poder desarrollar una relación intercultural.

"La intraculturalidad puede recrearse revalorizando la sabiduría y apoyando la autoestima de nuestros pueblos indígenas originarios, trabajo que debe ser priorizado en las universidades públicas introduciendo un nuevo tratado del ser en general (ontología), y una ciencia andina, maya o mapuche que trate el origen y a la naturaleza del conocimiento (gnoseología) y una epistemología de la unidad de indígenas, campesinos y/u originarios." (Delgado y Mariscal:220-221)

Este nuevo posicionamiento de los sectores indígenas frente a la sociedad mestiza-criolla permitió una nueva lectura, denunciar la colonialidad del saber y del poder. Indudablemente esto supuso un giro epistemológico que postulaba una descolonización mental y, por ende, una educación descolonizadora.

Sin duda, este nuevo quiebre epistemológico de la interculturalidad se alimentaba, por un lado, de los denominados "estudios culturales" que surgieron en las décadas de los ' 80 y '90 del siglo XX (Castro-Gómez, 2002). Y por otro, recogió las posturas poscoloniales o decoloniales, que comenzaron también a discutirse en los ' 90 en los espacios académicos. Dentro de esta corriente de pensamiento se encontraban intelectuales como Enrique Dussel, Walter Mignolo, Aníbal Quijano, Xavier Albó, Carlos Rincón, Raquel Olea, entre otros, cuyas investigaciones se centraban en los sujetos subalternos, entre ellos los grupos indígenas (Verdesio, 1997).

Cabe señalar que los estudios subalternos surgieron a partir de la historiografía india, cuyo mejor representante es RanajitGuha, quien a su vez interpretó una terminología extraída de Gramsci: las clases subalternas. Dicha categoría fue adoptada por un colectivo de investigadores residentes en los Estados Unidos que se dedicaban a estudiar literatura y cultura latinoamericanas. Entonces comenzó a utilizarse la idea de sujetos subalternos, convirtiéndose así en una poderosa herramienta teórica (Verdesio, 1997).

Aníbal Quijano (1989) sustentaba que, dentro de la denominada colonialidad del poder, las poblaciones amerindias y negras de América Latina fueron sometidas a un eurocentrismo y quedaron atrapadas entre un patrón epistemológico indígena y un patrón europeo-occidental. Pese a ello, estas poblaciones encontraron la manera de subvertir aquello que tenían que imitar, simular o venerar, pues hallaron en la expresión plástica-visual-artística (pintura, tejidos, orfebrería, cerámica, etc.) la manera de manifestar su propio pensamiento y cosmovisión. 
Por otro lado, Verdesio (1997) advirtió sobre los peligros inherentes a las teorías provenientes del mundo anglosajón, pues son portadoras de contenidos opresores e imperialistas. Su posición estaba en relación con el desplazamiento de las ideas, dado que cuando las teorías viajan a través de las fronteras culturales se "descontextualizan", sobre todo al entrar en contacto con realidades diferentes para las que no fueron pensadas. Es por ello que sugirió estar alertas ante la posibilidad de utilizar teorías que provengan del Viejo Mundo para analizar los contextos latinoamericanos, ya que estas podrían distorsionar la realidad que se pretende estudiar.

Lo que se persigue es que el conocimiento que se produzca no tenga características coloniales o neocoloniales y, en particular, que se permita la entrada de los saberes no-occidentales. En los últimos años se ha insistido mucho en construir sociedades más inclusivas, y en ese aspecto el rol de las universidades es preponderante ya que pueden ofrecer "otras" competencias. Es así que cobra importancia la "colaboración intercultural" (Mato, 2013), puesto que es fundamental que estos centros de investigación que producen conocimientos científicos de carácter universal puedan realizar sus prácticas en otros contextos y generar nuevas ideas consideradas como locales o particulares.

Dichos saberes estarían depositados en los pueblos indígenas, por ello se hace cada vez más necesaria la consulta en los proyectos de investigación y no solo eso, sino su incorporación a los mismos. Sin duda que esta participación indígena es un punto de inflexión en los estudios poscoloniales o decoloniales, ya que a través de esas prácticas se podrá, o más bien se deberá, intentar descolonizar las disciplinas (Verdesio, 1997). La idea que se plantea es un cambio de episteme; antes de los estudios poscoloniales se consideraba al indígena un mero objeto de estudio, a partir de este nuevo paradigma se reconoce que los pueblos indígenas poseen otra visión del mundo, diferente de la nuestra, además de ser, obviamente, un grupo social con derecho propio.

Al respecto debemos reconocer que dentro de algunas universidades de nuestro país el conocimiento indígena se ha ido introduciendo en algunos contenidos curriculares, sobre todo en las carreras de Historia, Antropología, Sociología y Arqueología. Sin embargo, el tratamiento de algunos temas sigue mereciendo un debate, en especial porque los intelectuales indígenas afirman que aún se reproduce un discurso hegemónico y una versión oficial de la historia (Prada y López, 2009).

Por su parte, Boaventura de Sousa Santos (2006) argumenta por una nueva forma de construir el conocimiento, reorientándolo hacia una mayor horizontalidad, que supere las jerarquías y que sea más colaborativo. Para este autor, el espacio de las universidades sería propicio para que se dé esta nueva manera de de-construir y cimentar los conocimientos, pues considera que allí es factible que se produzca un encuentro sistemático entre científicos sociales y líderes de los movimientos sociales, en este caso los indígenas. Tal como propone en su enfoque sobre la "ecología de los saberes", entendida como una contraepistemología o, al decir del autor, un "epistemicidio", reconoce una pluralidad de pensamientos heterogéneos frente a una concepción monocultural del conocimiento, donde lo central es la relación con el mundo real.

En esta línea, De Sousa Santos aboga por una nueva forma de investigación-acción, es decir que se trasladen los conocimientos desde afuera hacia la universidad, e inclusive piensa en otros espacios de debate, esto es, que se salga de la órbita de los claustros universitarios. 
Las universidades, a través de la extensión, pueden

"promover la apropiación social del conocimiento y la democratización del capital social y cultural, aspectos claves para contribuir a la transformación social, integrándose de este modo al medio social del cual se nutre y al que permanentemente contribuye, consciente y comprometida con las problemáticas sociales, culturales y productivas de la región en la que se encuentra inserta". (Menéndez, 2013:84)

No debemos olvidar que en las acciones de extensión se pone en juego una serie de variables: los contextos donde se producen, circulan e inciden los conocimientos, los cuales permitirán interpelar la realidad, el diálogo entre los saberes científicos con aquellos generados en los medios en los que se trabaja, de manera que todo esto contribuya a enriquecer los procesos de intervención.

\section{La Educación Intercultural Bilingüe en el sistema educativo argentino}

Si analizamos la situación en Argentina, queda claro que el advenimiento de la democracia en nuestro país abrió un camino que llevó al reconocimiento de la diversidad étnico-cultural $\mathrm{y}$, sobre todo, a afirmar su preexistencia. Pese a que a lo largo de nuestra historia esta condición de diversidad no ha sido plenamente reconocida por el sistema educativo, dado que las políticas educativas en nuestro país han estado signadas desde la etapa de la formación del Estado nacional por una clara tendencia hacia la homogeneización (Sulca, 2018a).

En Argentina, el derecho a una Educación Intercultural Bilingüe (EIB) es un hecho a partir de la nueva Ley de Educación Nacional sancionada a fines de 2006, la que en su artículo 53 establece y define esta nueva modalidad educativa. La mencionada norma explica que la EIB

"es la modalidad del sistema educativo de los niveles de Educación Inicial, Primaria y Secundaria que garantiza el derecho constitucional de los pueblos originarios, conforme al Art. $75^{\circ}$, inciso 17 de la Constitución Nacional, a recibir una educación que contribuya a preservar y fortalecer sus pautas culturales, su lengua, su cosmovisión e identidad étnica, a desempeñarse activamente en un mundo multicultural y a mejorar su calidad de vida". (Ministerio de Educación de la Nación, 2008:1)

Es en este contexto que se atiende el derecho de las poblaciones indígenas a una educación intercultural bilingüe en virtud de la demanda sentida de las comunidades originarias del país.

La construcción y el desarrollo de la EIB en Argentina fue producto de una motivación del Estado nacional dentro de un contexto de demanda general de los pueblos indígenas en América Latina. En ese sentido, podemos afirmar que en el andamiaje de la ElB hubo más participación de los equipos ministeriales, la academia, sectores privados (ONG) y una reducida participación de los pueblos indígenas. Es decir que persiste una brecha profunda de inequidad, una democracia limitada y excluyente, una marcada discriminación y racismo encubierto, marginación; en síntesis, existe una colonialidad vigente.

Dentro de las instituciones educativas, al menos en Argentina, las relaciones interétnicas siguen siendo asimétricas. Así pues, existe una lengua y cultura hegemónica que termina imponiéndose frente a otras lenguas y culturas subordinadas. No podemos negar que estas 
relaciones desiguales se construyeron históricamente, al menos desde la conformación de un proyecto de Estado-nación que hunde sus raíces en la segunda mitad del siglo XIX.

En el caso de las universidades argentinas, pese a sus autonomías y a ser centros de pensamiento crítico, estas han reflejado aquel modelo asimilacionista, monocultural y monolingüe. Si bien la equidad y la inclusión constituyen uno de sus compromisos esenciales, al menos dentro de la UNT, se hace necesario cada vez más diseñar y proponer acciones que incluyan y atiendan a los estudiantes indígenas. Debemos aclarar que hasta el presente no existen estudios previos sobre identificación de alumnos indígenas y pocas son las experiencias desarrolladas, dentro de la Universidad mencionada, que asistan aquellas demandas.

\section{Debates actuales sobre la interculturalidad}

Es menester implementar a futuro una educación intercultural en las aulas universitarias, que permita trascender las mallas curriculares, que se impregne de las relaciones sociales y se proyecte hacia la sociedad en su conjunto; de este modo se haría posible la utopía de la unidad en la diversidad (López y Rojas, 2006).

"La interculturalidad va más allá de las relaciones entre culturas. Supone el reconocimiento del otro y la afirmación de sí mismo", nos dice la lingüista ecuatoriana Ruth Moya (2009:28). Esta reflexión nos remite a pensar en nuestra propia construcción identitaria. ¿Quiénes somos? ¿Dónde están nuestros orígenes como sociedad? Para ello debemos apelar a elementos cohesionadores, vinculados a la historia común, a las relaciones con el entorno, los valores, las creencias y la lengua, los cuales deben ser valorados y resignificados.

En la actualidad se discute sobre los alcances de la EIB, es decir, ¿la interculturalidad es para todos? Si bien desde un inicio se planteó que estaba dirigida a educandos procedentes de pueblos, culturas y lenguas minorizadas con el propósito de contribuir a recuperar su autoestima, como también a preservar su lengua y cultura, la EIB lentamente comienza a trascender la esfera indígena para penetrar con sus ideas y propuestas al resto de la educación y la sociedad latinoamericanas. Todo esto en un momento histórico de los pueblos y nacionalidades indígenas, los cuales conviven en un mundo diverso y diferenciado; en ese sentido cobran fuerzas proyectos y consensos comunes que apuntan a una mejor convivencia.

Sin embargo, debemos aceptar que las propuestas de interculturalidad para todos los estudiantes siguen ancladas en el plano discursivo y no en la práctica. Por ello, uno de los desafíos inminentes es pensar y diseñar mecanismos que permitan llevar la interculturalidad tanto dentro de los diseños curriculares como dentro de la práctica áulica.

Esta idea se sustenta si pensamos que en nuestra provincia el aporte de los pueblos originarios prehispánicos constituye el sustrato de nuestra identidad cultural y del cual poco conocemos. Esto no está vinculado a una insuficiente investigación sino a la transferencia de estos conocimientos en el sistema educativo.

El desafío intercultural en las universidades es, por un lado, integrar el paradigma de los pueblos indígenas y, por el otro, introducir nuevas estrategias metodológicas para construir y transmitir conocimientos. En la medida en que esto se logre, se podrá superar la concepción hegemónica monocultural tan arraigada en nuestras universidades. 


\section{El proyecto Cátedra Libre: Pueblos Originarios}

La diversidad cultural está presente en nuestras aulas universitarias, lo que nos lleva a interpelarnos acerca de ¿qué condiciones de acceso, permanencia y egreso brindamos en nuestra universidad para atender a los estudiantes indígenas? ¿Cómo atendemos esa diversidad socioétnica? ¿Qué ofertas de formación superior ofrecemos para este colectivo social?

El problema radica en que las universidades no están preparadas para recibir un estudiantado con una impronta cultural diversa. Jung dice: "El problema no es la diversidad de los usuarios del sistema educativo, sino la incapacidad de éste para responder a las necesidades específicas, para permitir el crecimiento de los niños y de sus sociedades" (1994:277).

Aunque la universidad apunta a integrar a los jóvenes dentro de su proyecto político-educativo, ella no se interpela sobre la especificidad étnica de ese alumnado, ni siquiera sobre cómo se incorporan, reciben y transforman los saberes que acogen (Hirsch, 2010).

La procedencia del alumnado que llega a la Facultad de Filosofía y Letras de la UNT es variado, pues pertenece a las comunidades: diaguita-calchaquí, kolla y aymara. Sin embargo, conviene señalar que en su gran mayoría llegan a la universidad sin autorreconocerse. El primer paso de este proyecto fue acompañar el proceso de autorreconocimiento a través de una entrevista y el llenado de una encuesta (ambas actividades fueron con carácter voluntario). Se tuvo en cuenta la procedencia de los apellidos, aunque sabemos que no es el único indicador, pero al menos se logró que en la ficha de ingreso a la Facultad se colocara una pregunta sobre la pertenencia étnica del alumnado. Sabemos que trabajar solo con los apellidos nos limitó, sobre todo cuando entendemos que hay alumnos indígenas que no portan apellidos reconocidos en las lenguas originarias.

A continuación, reproducimos la ficha utilizada para relevar la presencia de alumnos indígenas en la Facultad:

\section{Ficha de relevamiento de alumnos pertenecientes a comunidades indígenas}

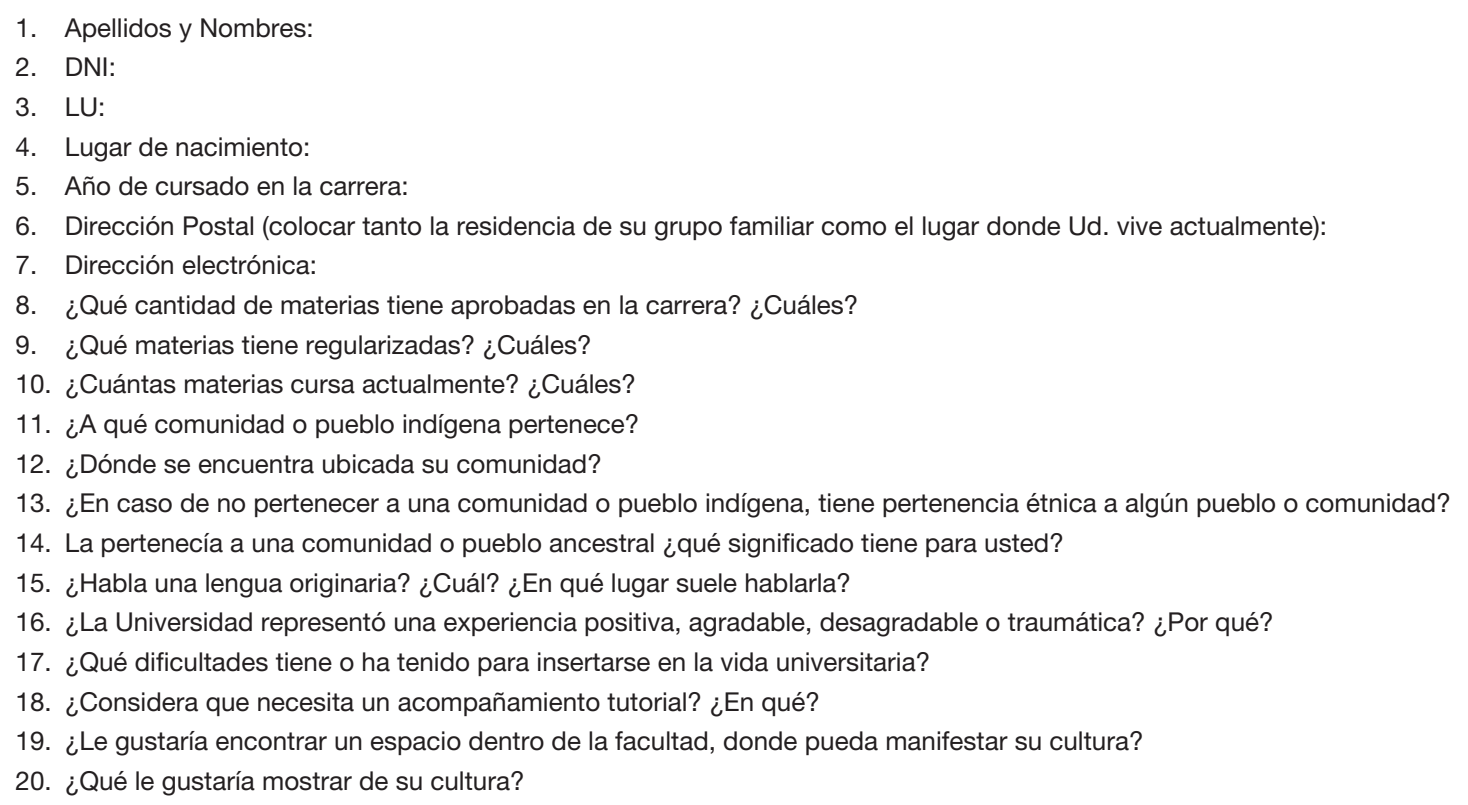

Fuente: Sulca (2018b). 
Una segunda instancia de la propuesta estuvo centrada en armar una mesa de diálogo y construcción conjunta del proyecto: la creación de una cátedra libre de Pueblos Originarios dentro de la universidad. Este proceso de participación fue clave para garantizar el éxito del emprendimiento, pues la relación y el contacto periódico con los distintos miembros de las organizaciones indígenas permitieron que las comunidades se empoderasen en este espacio. Seguidamente, en el Cuadro 1, detallamos las comunidades existentes, las cuales participaron del mencionado proyecto.

Cuadro 1. Comunidades participantes del proyecto.

\begin{tabular}{|c|c|c|c|}
\hline \multicolumn{2}{|c|}{ Comunidad } & \multirow{2}{*}{$\begin{array}{l}\text { Departamento } \\
\text { Tafí del Valle }\end{array}$} & \multirow{2}{*}{$\begin{array}{l}\text { Cantidad de familias } \\
873\end{array}$} \\
\hline 1 & Indígena Amaicha del Valle & & \\
\hline 2 & India Quilmes & Tafí del Valle & 593 \\
\hline 3 & Indígena Diaguita del Valle de Tafí & Tafí del Valle & 667 \\
\hline 4 & Indígena Diaguita El Mollar & Tafí del Valle & 435 \\
\hline 5 & Indígena La Angostura & Tafí del Valle & 105 \\
\hline 6 & Indígena de Casa Viejas & Tafí del Valle & 105 \\
\hline 7 & Indígena Ayllu El Rincón & Tafí del Valle & 50 \\
\hline 8 & Indígena de Mala Mala & Tafí del Valle & 20 \\
\hline 9 & Indígena Pueblo de Tolombón & Trancas & 257 \\
\hline 10 & Indígena de Chuschagasta & Trancas & 84 \\
\hline & Indígena Potrero Rodeo Grande & Trancas & 101 \\
\hline 12 & Indio Colalao & Trancas & 60 \\
\hline 13 & Indígena de Anfama & Tafí Viejo & 84 \\
\hline 14 & Indígena de Chasquivil & Tafi Viejo & 100 \\
\hline 15 & Indígena de Solcos Llampa & Chicligasta & 10 \\
\hline 16 & Indígena El Nogalito & Lules & 75 \\
\hline TO & TAL & & 3619 \\
\hline
\end{tabular}

Fuente: Instituto Nacional de Asuntos Indígenas, Tucumán (2008); Sulca (2018a).

Las mediaciones, los acuerdos y las negociaciones entre los distintos actores del proyecto jugaron un papel clave en el armado de las clases que se iban a dictar. Estas decisiones atravesaron las dimensiones institucional, curricular y epistemológica. El reto que nos proponíamos fue poner en marcha una perspectiva intercultural que exija no solo la visibilización de lo indígena sino reposicionar el conocimiento indígena desde un enfoque decolonial. 
El 9 de octubre de 2009 inauguramos la cátedra libre de Pueblos Originarios. A su apertura asistieron la decana de la Facultad de Filosofía y Letras, Dra. Elena Rojas Mayer; el decano de la Facultad de Ciencias Naturales, Dr. Ricardo Mon; el presidente de la Unión de los Pueblos de la Nación Diaguita, Sr. Delfín Gerónimo; y el cacique de la comunidad Indio Colalao.

La puesta en marcha del proyecto fue la expresión de una utopía materializada, pues era la primera vez que nuestra universidad abría un espacio para las comunidades indígenas de nuestro territorio provincial.

La mencionada cátedra funcionó con encuentros mensuales donde se abordaron problemáticas heterogéneas; dichas reuniones fueron planificadas al iniciarse cada año lectivo y estuvieron bajo la responsabilidad de algunos comuneros o dirigentes indígenas y también académicos. A modo de ejemplo, en la Tabla 1 detallamos un cronograma construido durante el año 2015.

Tabla 1. Cronograma para el año 2015.

\begin{tabular}{|c|c|c|}
\hline Día & Tema & Responsable \\
\hline 4/5/2015 & Jóvenes indígenas & ANDHES y miembros de la comunidad de Amaicha del Valle \\
\hline 2/6/2015 & Educación Intercultural Bilingüe & $\begin{array}{l}\text { Consejo Educativo Autónomo de los Pueblos Indígenas } \\
\text { y de la comunidad de Amaicha del Valle }\end{array}$ \\
\hline $7 / 7 / 2015$ & Territorio e Impacto ambiental & Comunidad de Solcos Llampa y ANDHES \\
\hline $31 / 7 / 2015$ & Territorio y Gobernabilidad & Comunidad de Amaicha del Valle y ANDHES \\
\hline $1 / 9 / 2015$ & La Copla: música tradicional & Grupo Acoplase \\
\hline $6 / 10 / 2015$ & Patrimonio cultural y Pueblos Originarios & Unión de los Pueblos de la Nación Diaguita \\
\hline $3 / 11 / 2015$ & Universidad y Pueblos Originarios & Grupo Fogón Andino \\
\hline
\end{tabular}

Fuente: elaboración propia.

Desde su creación y hasta 2014, las clases se impartieron dentro de la ciudad de San Miguel de Tucumán, y desde 2014 a 2016 la cátedra funcionó dentro de los territorios indígenas, respondiendo a una demanda de las propias comunidades. De esta manera, la cátedra comenzó su itinerancia por la comunidad de Amaicha del Valle (departamento de Tafí del Valle, Tucumán), la comunidad de Solcos LLampa (departamento Concepción, Tucumán), la comunidad de Chuschagasta (departamento de Trancas, Tucumán), etc. Los objetivos que nos planteamos fueron los siguientes:

- Avanzar en nuevas discusiones epistemológicas, que sitúen el conocimiento desde los pueblos indígenas.

- Involucrar en los espacios de discusión de la cátedra a actores sociales que ocupen cargos de gestión o bien que tengan poder de decisión.

- Respetar y valorar los aportes culturales de los diversos grupos étnicos que conviven dentro del territorio provincial y nacional. 
- Impulsar la valoración y recuperación de los conocimientos ancestrales, aportar esfuerzos para sistematizarlos y documentarlos.

- Conocer, analizar y reflexionar sobre los derechos jurídicos que amparan a los pueblos originarios.

- Fomentar y propiciar un espacio de encuentro y discusión entre las diferentes comunidades indígenas y los alumnos de la Facultad de Filosofía y Letras.

- Identificar y reflexionar sobre los contextos en que se desarrollan los conocimientos los niños y jóvenes indígenas.

En cuanto a las actividades que se efectuaron paralelamente al desarrollo de las clases, fueron:

- Proyecciones de películas vinculadas a las comunidades indígenas, tanto nacionales como de Latinoamérica.

- Organización de talleres y mesas paneles cuyas temáticas fueron variadas: las mujeres indígenas, las prácticas culturales, la cosmovisión indígena, la medicina intercultural, la educación intercultural bilingüe, el territorio para las comunidades indígenas, la copla y las expresiones artísticas, el tejido andino: tradición y modernidad, los avances judiciales en materia de restitución de la tierra en la provincia de Tucumán, etcétera.

- Trabajo colaborativo junto a comunidades indígenas, cuyo objetivo fue compartir saberes y habilidades. Durante 2015 se efectivizó un trabajo de campo junto a, con y en la comunidad Wichi de Morillo (Salta). Este trabajo de campo involucró a alumnos de diversas carreras (Historia, Ciencias de la Educación, Ciencias de la Comunicación, Filosofía y Trabajo Social). El propósito de esta tarea se direccionó, por un lado, a intercambiar conocimientos con la comunidad Wichi situados dentro de un cambio de episteme. Y, por otro lado, a acercarnos a una comunidad indígena para aprender, valorar y conocer sus prácticas culturales y, en especial, su lengua. Este trabajo fue ejecutado en dos momentos, durante julio y octubre, y en ambos contactos se llevó a cabo una importante labor interdisciplinaria, pues se trabajó conjuntamente con un equipo de la Facultad de Odontología. La actividad en terreno fue diversa: desde talleres dirigidos a niños y jóvenes sobre cuidado del medioambiente y la historia hasta juegos recreativos y deportivos. Para los docentes de las escuelas donde se implementa la EIB, se dictaron talleres de capacitación sobre sus fundamentos y su aplicación a través de propuestas áulicas. De manera paralela, en las comunidades se pusieron en marcha actividades de prevención e intervención bucal. Luego de las mencionadas acciones, que se efectivizaban durante el día, por la noche, en la plaza de la localidad de Morillo, se proyectaba un ciclo de cine dirigido a los niños. El contacto con la comunidad wichi representó para los estudiantes una significativa experiencia, ya que pudieron establecer una relación interactiva con los miembros de la comunidad a través del intercambio, la participación y la construcción de redes interculturales en la práctica. Pudieron interpelar los conocimientos adquiridos en la universidad y los que encontraron en terreno. Con posterioridad, toda la tarea desarrollada en la comunidad fue socializada en el ámbito universitario en donde el impacto fue muy motivador y convocante para otros alumnos. En una entrevista, los estudiantes de la UNT que tuvieron la experiencia de conocer una comunidad wichi desde adentro manifestaron, por ejemplo: "Estamos muy contentos por estar con una cultura viva. Compartir cosas con ellos, aprender con ellos", contó Julio Córdoba (alumno de la carrera de Historia). 
Desde 2016 al presente, la cátedra tejió una significativa alianza con el Instituto de Rescate y Revalorización del Patrimonio Cultural (CERPACU), para forjar conjuntamente mesas, paneles, debates, proyecciones de películas e intervenciones artísticas y sobre todo para visibilizar problemáticas actuales de las comunidades, como fue la cuestión mapuche. Las actividades emprendidas en conjunto con el mencionado Instituto se sistematizan en la Tabla 2:

Tabla 2. Actividades vinculadas al CERPACU.

\begin{tabular}{|c|c|c|c|c|}
\hline Año & Actividad & Propósito & Participantes & Conclusiones \\
\hline \multirow[t]{2}{*}{2017} & $\begin{array}{l}\text { Mesa panel: "Mujeres in- } \\
\text { dígenas en la actualidad. } \\
\text { Lengua, cultura e identidad } \\
\text { desde una perspectiva de } \\
\text { género". }\end{array}$ & $\begin{array}{l}\text { Fomentar y propiciar un } \\
\text { espacio de encuentro y dis- } \\
\text { cusión. }\end{array}$ & $\begin{array}{l}\text { Cátedra Libre de Pue- } \\
\text { blos Originarios, Cáte- } \\
\text { dra Lenguas Indígenas, } \\
\text { CERPACU y Cátedra de } \\
\text { Etnología. }\end{array}$ & $\begin{array}{l}\text { Recuperar las voces calladas, silenciadas } \\
\text { y desprovistas de opiniones, para visibili- } \\
\text { zar su presencia en el mundo indígena y } \\
\text { no indígena. }\end{array}$ \\
\hline & $\begin{array}{l}\text { Mesa Panel: “Agonías y } \\
\text { Resistencias del Pueblo } \\
\text { Mapuche”. }\end{array}$ & $\begin{array}{l}\text { Gestar espacios de debate } \\
\text { sobre la problemática ac- } \\
\text { tual del pueblo mapuche y } \\
\text { de-construir las versiones de } \\
\text { los medios de comunicación } \\
\text { oficiales, que estigmatizan a } \\
\text { nuestros pueblos originarios. }\end{array}$ & $\begin{array}{l}\text { Cátedra Libre de } \\
\text { Pueblos Originarios, } \\
\text { Cátedra Lingüística } \\
\text { General II, CERPACU } \\
\text { y Comunidad Indígena } \\
\text { del Mollar. }\end{array}$ & $\begin{array}{l}\text { La reflexión histórica debe estar presente } \\
\text { en nuestros espacios académicos a fin } \\
\text { de visibilizar la historia no hegemónica } \\
\text { y cotejar con problemáticas actuales de } \\
\text { los pueblos originarios de Argentina que } \\
\text { aún siguen luchando contra el avance de } \\
\text { nuevos colonialismos. }\end{array}$ \\
\hline \multirow[t]{2}{*}{2018} & $\begin{array}{l}11 \text { de octubre: Ciclo de } \\
\text { cine -debate: "Pueblos } \\
\text { Originarios" } \\
\text { - Octubre Pilagá (directora: } \\
\text { Valeria Mapelman). } \\
\text { - Los hijos de los valles (Co- } \\
\text { lección Canal Encuentro). }\end{array}$ & $\begin{array}{l}\text { Interpelar la historia oficial } \\
\text { con las historias descono- } \\
\text { cidas de los pueblos origi- } \\
\text { narios. }\end{array}$ & $\begin{array}{l}\text { Cátedra Libre de Pue- } \\
\text { blos Originarios y CER- } \\
\text { PACU. }\end{array}$ & $\begin{array}{l}\text { Reflexionar sobre las formas en que se } \\
\text { producen, transmiten y reproducen los } \\
\text { conocimientos; los cuales formaron parte } \\
\text { de la historia oficial. }\end{array}$ \\
\hline & $\begin{array}{l}2 \text { de noviembre: Celebra- } \\
\text { ción del Día de las Almas/ } \\
\text { Día de Muertos }\end{array}$ & $\begin{array}{l}\text { Esta propuesta se fundamen- } \\
\text { ta en la idea de resignificar y } \\
\text { dar visibilidad a las prácticas } \\
\text { culturales de nuestra comuni- } \\
\text { dad y de los pueblos origina- } \\
\text { rios quienes homenajean para } \\
\text { esta época de una manera } \\
\text { particular a sus muertos. }\end{array}$ & $\begin{array}{l}\text { Cátedra Libre de Pue- } \\
\text { blos Originarios y CER- } \\
\text { PACU. }\end{array}$ & $\begin{array}{l}\text { Asumimos el compromiso de gestar } \\
\text { espacios en nuestra facultad, con el } \\
\text { propósito de que las comunidades exis- } \\
\text { tentes en nuestro territorio puedan difun- } \\
\text { dir aspectos de su patrimonio cultural e } \\
\text { identidad. }\end{array}$ \\
\hline \multirow[t]{2}{*}{2019} & $\begin{array}{l}\text { Charla debate: Día Interna- } \\
\text { cional de la Eliminación de la } \\
\text { Discriminación Racial. }\end{array}$ & $\begin{array}{l}\text { El propósito es realizar } \\
\text { conjuntamente, actos con- } \\
\text { memorativos en el Día Inter- } \\
\text { nacional de la eliminación } \\
\text { de la discriminación racial } \\
\text { en distintas universidades } \\
\text { miembro de la Coalición } \\
\text { interinstitucional de la Inicia- } \\
\text { tiva, así como en la UNESCO } \\
\text { en su sede en París. }\end{array}$ & $\begin{array}{l}\text { Cátedra Libre de } \\
\text { Pueblos Originarios, } \\
\text { CERPACU y la Cátedra } \\
\text { UNESCO Educación Su- } \\
\text { perior y Pueblos Indíge- } \\
\text { nas y Afrodescendientes } \\
\text { en América Latina del } \\
\text { Centro Interdisciplinario } \\
\text { de Estudios Avanzados } \\
\text { (CIEA). }\end{array}$ & $\begin{array}{l}\text { Esta iniciativa se propone contribuir a } \\
\text { erradicar todas las formas de racismo } \\
\text { y discriminación racial en la Educación } \\
\text { Superior, poniendo especial énfasis en } \\
\text { aquellas que afectan especialmente a } \\
\text { las personas y comunidades indígenas y } \\
\text { afrodescendientes. }\end{array}$ \\
\hline & $\begin{array}{l}\text { Conversatorio: "La Cons- } \\
\text { trucción de nuevos paradig- } \\
\text { mas indígenas en la Educa- } \\
\text { ción Superior e Investigación } \\
\text { (Caso Boliviano)". }\end{array}$ & $\begin{array}{l}\text { Compartir experiencias edu- } \\
\text { cativas de otros países. }\end{array}$ & $\begin{array}{l}\text { Cátedra Libre de Pue- } \\
\text { blos Originarios y CER- } \\
\text { PACU. }\end{array}$ & $\begin{array}{l}\text { La experiencia compartida por el Dr. Yamil } \\
\text { Adolfo Vera sobre el caso boliviano, sus- } \\
\text { citó un interesante debate que supero el } \\
\text { aspecto ontológico para reflexionar sobre } \\
\text { todos los aspectos de la cultura de los } \\
\text { pueblos originarios. }\end{array}$ \\
\hline
\end{tabular}

Fuente: elaboración propia. 
Finalmente, podemos destacar la participación en las diferentes actividades de estudiantes indígenas y de no indígenas, como también de alumnos de otras carreras universitarias (Derecho, Medicina, Arte y Arqueología), e incluso un público general interesado en estas temáticas. Es indudable que para los estudiantes de ascendencia indígena la experiencia les permitió no solo fortalecer su identidad sino tomar conciencia de su pertenencia étnica. Pero también les significó adquirir un bagaje significativo de conocimientos que contribuirá a su formación profesional. De esto último, rescatamos la importancia de que estos aprendizajes puedan obtenerse fuera de los claustros universitarios y que, por el contrario, estuvieran en los territorios indígenas y, más aún, con sus protagonistas.

El trabajo conjunto con miembros de las comunidades indígenas y otras organizaciones (Fogón Andino, Acoplase, Abogados y Abogadas del Noroeste Argentino en Derechos Humanos y Estudios Sociales) implicó poner en práctica consensos y acuerdos cuyos resultados fueron las clases compartidas, las decisiones asumidas en la selección de las mesas paneles y la evaluación de los costos y beneficios que suponía la itinerancia de la cátedra. Consideramos que lo más valioso fue el intercambio y la colaboración entre diversas formas de saber, aquello que Mato (2013) denomina "colaboración intercultural". La importancia de estas relaciones entre diversos actores sociales estuvo dada por las formas de ver el mundo, producir conocimientos y resolver problemas, y su resultado fueron nuevos contextos y saberes. Como resultado de ello también surgieron nuevas líneas de investigación en nuestros proyectos y la producción de materiales escritos en conjunto: Nuestro Tucma y Nuestro Tucma II, ambos en coautoría con miembros de las comunidades y dirigidos a los niños de las escuelas de nivel primario.

\section{Consideraciones finales}

La idea principal que sugieren los estudios poscoloniales o subalternos es que las investigaciones en el campo de la arqueología, antropología e historia contribuyan a avanzar en la causa o causas indígenas, lo que ayudaría a repensar el rol del intelectual en la sociedad y su relación con los sujetos subalternos que estudia. Para ello, hay que superar el conflicto entre saberes expertos y saberes subyugados. Si no se resuelve este problema, estaremos subalternizando los saberes de los grupos étnicos. Por ello se hace necesario utilizar los saberes de los pueblos indígenas para la construcción o reconstrucción del pasado.

En suma, lo que aquí planteamos y lo que aprendimos con la experiencia de trabajar a lo largo de 10 años con las distintas comunidades existentes en la provincia de Tucumán, es que una educación intercultural en la universidad nos impone un re-centramiento ideológico y epistemológico.

Hoy la interculturalidad y sus proyectos enfrentan situaciones bastante complejas y surge una serie de interrogantes acerca de la posibilidad de construir y desarrollar políticas educativas en una sociedad multicultural en la que no se impongan institucionalmente modelos de subordinación de unos sectores de la población sobre otros bajo una supuesta lógica de "reconocimiento" (Sulca, 2018b).

La universidad articulada dentro de un contexto sociocultural y, en el caso particular, de la Facultad de Filosofía y Letras de la UNT, como institución formadora de profesionales en la docencia e investigación, debe contribuir y fortalecer los procesos de resistencia, 
revitalización cultural y recuperación de la identidad cultural y valorar las cosmovisiones y pensamientos de los pueblos indígenas. De hecho, a partir de estas acciones concretas que desarrollamos en el presente trabajo, avanzamos en cuanto a situar ese conocimiento indígena desde otro posicionamiento (Sulca, 2018b).

La presencia de la cátedra libre de Pueblos Originarios nos permitió reflexionar e intervenir sobre los procesos de inclusión de los alumnos indígenas que asisten a nuestra unidad académica. Se sostuvo que no solo existe un problema de acceso sino que las desigualdades son más profundas. Así, un estudiante universitario afirmó que "no es un problema de acceso, es un problema de la invisibilidad de los indígenas en la universidad. Además los indígenas entran indios y salen blancos" (Bello, 2009:484)

Finalmente, dado el ejercicio dialógico que nos implicó el proyecto, nos sirvió para reconocer y aceptar que las lógicas indígenas son sistemas propios de pensamiento y nos propuso una revisión crítica de nuestras epistemologías.

Queda claro que las prácticas de extensión tienen un gran potencial educativo dado que permiten crear nuevos conocimientos (Menéndez, 2013) y, sobre todo, posibilita a alumnos y docentes aprender e interpelar los conocimientos en terreno.

\section{Referencias bibliográficas}

Bello, A. (2009). Universidad, pueblos indígenas y educación ciudadana en contextos multiétnicos en América Latina. En López, L.E. (Ed.). Interculturalidad, educación y ciudadanía. Perspectivas latinoamericanas. La Paz: Plural editores, FUNPROEIB Andes.

De Castro-Gómez, S. (2002). Historicidad de los saberes, estudios culturales y transdisciplinariedad: reflexiones desde América Latina. En Flores, A. y Millán, C. (Eds.). Desafíos de la transdisciplinariedad. Bogotá: CEJA. Delgado, F. y Mariscal, J. (2007). Educación Intra e Intercultural. Alternativas a la reforma Educativa Neocolonizadora. La Paz: Agrupo-Compas.

Hirsch, S. (2010). Pensando la EIB en contextos pluriétnicos y plurilinguísticos. En Hirsch, S. y Serrudo, A. (Comps.). La ElB en Argentina. Identidades, lenguas y protagonistas. Buenos Aires: Noveduc.

Jung, I. (1994). Propuesta de formación del maestro bilingüe. Lima: Foro Educativo.

López, L.E. (1999). Interculturalidad, educación y política en América Latina: perspectivas desde el Sur. En López, L.E. (Ed.). Interculturalidad, educación y ciudadanía. Perspectivas latinoamericanas. La Paz: Plural editores, FUNPROEIB Andes.

(2004). Interculturalidad y educación en América Latina: Lecciones para y desde la Argentina. En Educación Intercultural Bilingüe. Sistematización de Experiencias. Buenos Aires: Ministerio de Educación, Ciencia y Tecnología.

López, L.E. y Rojas, C. (2006). La ElB en América Latina bajo examen. La Paz: Plural editores.

Mato, D. (2013). Aprendizajes de equipos universitarios en experiencias de colaboración con comunidades y organizaciones sociales realizadas con apoyo del Programa Voluntariado Universitario de Argentina, 2008. Apuntes 72: Revista de Ciencias Sociales. Universidad del Pacífico, Lima, Perú.

Menéndez, G. (2013). Institucionalización de la extensión. Conceptualización y dimensiones de la extensión. En http://bibliotecavirtual.unl.edu.ar/colecciones/handle/123456789/7967 (consultado el 9 de junio de 2019). Ministerio de Educación de la Nación (2008). Modalidad Educación Intercultural Bilingüe. Documento para la discusión. Modalidad EIB en el sistema Educativo Nacional. Documento para la discusión, junio. Buenos Aires: Instituto Nacional de Formación Docente (INFOD). 
Moya, R. (2009). La interculturalidad para todos en América Latina. En López, E. (Ed.). Interculturalidad, educación y ciudadanía. Perspectivas latinoamericanas. Bolivia: Plural editores, FUNPROEIB Andes.

Prada, F. y López, L.E. (2009) Educación superior y descentramiento epistemológico. En López, L. E. (ed.) Interculturalidad, educación y ciudadanía. Perspectivas latinoamericanas, Bolivia: Plural editores, FUNPROEIB Andes.

Quijano, A. (1989) Colonialidad del poder, cultura y conocimiento en América Latina. Lima: Amauta.

Sousa Santos, B. de (2006). Renovar la teoría crítica y reinventar la emancipación social. Buenos Aires: CLACSO.

Verdesio, G. (1997). El subalternismo en el marco de la teoría arqueológica: hacia un posible dialogo entre matrices teóricas. Michigan: University of Michigan.

Sulca, O. (2018a). De la Banda Carroñera a las Jefaturas Prehispánicas. Manuales Humanitas. $3^{\circ}$ reedición. Tucumán: Facultad de Filosofía y Letras, UNT.

(2018b). Pueblos indígenas y universidad: hacia la formación de una ciudadanía diferente. En Abbona, A. y Roca, I. (Eds.). Los Pueblos Indígenas de América Latina: Actas del II CIPIAL. La Pampa: Universidad Nacional de La Pampa. EPUB. 